\section{MARSILIO FICINO, FRANCESCO CAVALLI E A MÚSICA COMO REMÉDIO PARA O DESGOSTO AMOROSO}

\author{
Jacomien Prins ${ }^{1}$
}

1. University of Warwick,
UK. Email: j.w.prins@ warwick.ac.uk

\title{
RESUMO:
}

Neste artigo, o filósofo Marsilio Ficino (1433-1499) e o compositor Francesco Cavalli (1602-1676) são apresentados como pertencentes a um e ao mesmo universo discursivo, no qual música, amor e imaginaçáo cumprem um papel fundamental. A teoria do amor Neoplatônica de Ficino exerce uma função central em sua filosofia. Ele define o amor como o desejo pela beleza. Coisas belas, como a música harmoniosa, inspiram a alma com amor. Quando a música é adequadamente apreciada, o amante se distancia do mundo sensível , foca sua atenção em sua alma e, com isto, encontra seu fim último em Deus. Contudo, se a alma ama de modo impróprio e se fixa na beleza sensual da música, o resultado é a doença amorosa. Assim, para Ficino, o uso adequado do amor e da música repousa no âmago da felicidade humana. Um eco secularizado desta teoria pode ser ouvido na ópera Artemisia, de Cavalli.

\section{PALAVRAS-CHAVE:}

Marsilio Ficino; Francesco Cavalli; imaginação; doença amorosa; terapia musical.

\footnotetext{
ABSTRACT:

In this article, the philosopher Marsilio Ficino (1433 - 1499) and the composer Francesco Cavalli (1602 - 1676) are presented as belonging to one and the same universe of discourse, in which music, love, and the imagination play a fundamental role. Ficino's Neoplatonic theory of love plays a central role in his philosophy. He defines love as the desire for beauty. Beautiful things such as harmonious music inspire the soul with love. When music is loved properly, the lover distances himself from the sensible world, focuses his attention on his soul, and thus ultimately finds his end in God. However, if the soul loves improperly and becomes fixated on
} 
the sensual beauty of music, this results in lovesickness. Thus, for Ficino, the proper application of love and music lie at the heart of human happiness. A secularized echo of this theory can be heard in the Cavalli's opera Artemisia.

\section{KEYWORDS:}

Marsilio Ficino; Francesco Cavalli; imagination; lovesickness; music therapy.

\section{INTRODUÇÃO}

No berço de inúmeras variaçôes sobre o tema da música como um remédio para o sofrimento amoroso na história da cultura ocidental, encontra-se o mito de Orfeu e Eurídice. O lendário Orfeu era admirado tanto na Renascença quanto no início da era moderna pelos seus poderes musicais sobrenaturais. $\mathrm{O}$ sofrimento amoroso em relação a Eurídice, sua amante morta, inspirou-o a cantar cançóes maravilhosamente expressivas. Essas cançóes, em que Orfeu acompanhava-se a si mesmo à lira, tinham táo excepcional beleza e força que pessoas, animais e até mesmo árvores e pedras ficavam por elas enfeitiçados. Quando Orfeu desceu ao submundo para trazer Eurídice de volta à terra dos vivos, ele logrou abrandar até mesmo o coração dos deuses do submundo. O fim trágico da história é conhecido: Eurídice seguiu Orfeu, sob a estrita condição de que ele, no caminho, não olhasse para trás. Mas Orfeu não conseguiu obedecer a esta exigência, e perdeu Eurídice novamente, mas, desta vez, para sempre.

No início do Renascimento é o amor por entendido filósofos como Marsilio Ficino (1433 - 1499) como uma força cósmica, à qual estão sujeitas não apenas as pessoas, mas todas as partes do cosmo. Em sua filosofia, teologia, ciência musical e medicina, ele atribui grande valor ao amor, devido à sua natureza universal e à sua força incontrolável. Em nítido contraste com esse tipo de amor, encontra-se o amor erótico humano, que, como força ambivalente, pode influenciar a vida humana tanto de forma positiva quanto negativa. Amor a Deus e amor ao próximo são aspectos da força harmonizadora e moderadora que pode levar a uma maior unidade, tranquilidade de ânimo e saúde. Paixão e desejos são aspectos de uma 
força psíquica devastadora que pode levar à desintegraçáo, ao desequilíbrio e às doenças, como o sofrimento amoroso. Nesse contexto, a música figura como terapia, em escritos como o De amore de Ficino (1469), e como um método para atuar na cura de formas prejudiciais de amor, para que estas possam dar lugar a formas benéficas.

No início da era moderna, o amor ainda era entendido por compositores como Francesco Cavalli (1602 - 1676) como uma das principais forças na vida emocional do homem. A terapia musical foi concebida em sua ópera Artemisia (1657), como um método rápido e eficaz para livrar a protagonista Artemisia de um desequilíbrio causado por um amor imoderado e para re-harmonizar seu espírito. Mas, nesta composição, a música, como remédio para o desgosto amoroso, já havia se transformado em um clichê, em que noçóes tradicionais sobre a harmonia do mundo e do amor como força cósmica ressoavam apenas vagamente. ${ }^{2}$

Neste artigo, discutirei em primeiro lugar a teoria de Ficino referente à terapia musical para tratamento do sofrimento amoroso, em que conceitos da tradição médica sobre doenças e saúde estáo intimamente ligados com noçóes da tradiçáo religiosa, nas quais o anseio pelo verdadeiro amor divino é central. Apresentarei essa teoria, em particular, no contexto da fé de Ficino na harmonia mundana, e na possibilidade por ele considerada de temperar a alma humana. Em seguida, discutirei o dueto "Cor mio che sarà" ("Meu coraçáo, o que acontecerá? `) de Artemisia, de Cavalli, para investigar como e por que ideias de filósofos como Ficino sobre a música como remédio para o sofrimento amoroso foram utilizadas para constituir o caráter de sua protagonista. Finalmente, na conclusão, na conclusão, adentrar-me ei na questáo a respeito da contribuiçáo que a comparação entre Ficino e Cavalli traz para a história antiga da terapia musical para a cura do desgosto amoroso.

\section{MÚSICA COMO CURA PARA O DESGOSTO NA FILOSOFIA RELIGIOSA DE FICINO}

Marsilio Ficino estava totalmente ciente de que a vida de um cientista ou um artista com uma imaginação facilmente inflamável trazia consigo todo o tipo de risco de desen-
2. Sobre uma introduçáo ao tema dos tratamentos musicais sobre o desgosto amoroso na história da cultura ocidental, cf. AUSTERN (2000, p. 195245). 
3. Para uma traduçáo inglesa desta carta, intitulada 'Medicina corpus, musica spiritus, theologia animum', cf. FICINO (1975, p. 609).

4. Sobre uma introduçấo à terapia musical de Ficino, cf. WALKER (2003 [1958], p. 3-24) e PRINS (2014, p. 186-206).

5. Sobre o tratamento clássico das ideias de Ficino a respeito da melancolia e da astrologia, cf. KLIBANSKY, PANOFSKY, SAXL (1964, p. 32ss e 49ss); cf. ainda FICINO (1944 [1469], XI, p. 229). volvimento de doenças psicossomáticas. Para se precaver de tais efeitos negativos, ele escreveu o primeiro livro de auto-ajudal para aqueles que desejassem trabalhar para a melhoria de sua saúde. Nesta obra, De vita triplici ("Três Livros sobre a Vida", 1489), a música desempenha um papel importante em todos os tipos de aconselhamento para a cura de doenças, assim como para promover a saúde e a felicidade. Para Ficino, a música não é apenas um fenômeno acústico, mas um importante evento espiritual, intelectual, emocional e social. Para entender seus conselhos a respeito do desgosto amoroso, é, portanto, importante saber que Ficino tem uma visão holística do homem. De acordo com esta visão, ele dispensa atenção à alma imortal, cujo cuidado é confiado a provedores espirituais, vigários e padres; a um corpo que pode ser curado pelos médicos, e a um espírito - uma substância (energia, élan vital) intermediária entre corpo e alma - à qual músicos e musicoterapeutas podem influenciar da forma mais eficaz. ${ }^{3} \mathrm{~A}$ música tem um efeito direto sobre o espírito humano, porque a música sonante é considerada uma substância aérea ágil e dotada de espírito, muito semelhante ao spiritus humano ${ }^{4}$. $\mathrm{O}$ espírito de estudiosos e artistas necessita de cuidados e atenção extraordinários, uma vez que em sua atividade mental constante de pensar e imaginar, estes estudiosos consomem rapidamente a reserva de spiritus em seu sangue. Quando isto acontece, o spiritus precisa ser reposto pela reserva de spiritus no sangue, e, consequentemente, o sangue se torna espesso, seco e negro, devido à baixa dose de spiritus e à alta dose de bile negra. De acordo com Ficino, estudiosos e artistas geralmente se associam à bile negra e ao temperamento melancólico, desencadeado por uma combinação de disposição e de estilo de vida. O melancólico tem predisposiçáo para o desgosto amoroso e para a nostalgia, pois, com seu poder de imaginação facilmente inflamável, ele pode evocar com mundos e tempos que lhe parecem mais reais do que a realidade cotidiana. ${ }^{5}$ Como Ficino também vê a si mesmo como um homem melancólico, uma de suas maiores ambiçóes é a de compreender e fundamentar o efeito enigmático da música sobre a alma humana. Em sua filosofia, a música recebe o status de antídoto contra o sofrimento que advém da imperfeição da existência humana. 
Em De amore ("Sobre o Amor", 1484) Ficino apresenta suas ideias sobre a interação entre o amor, a harmonia cósmica e música. Ele toma como ponto de partida o Timeu 35b-36b, em que Platão afirma que os movimentos harmoniosos dos planetas e as harmonias na música sonante são manifestaçóes de harmonias arquetípicas na Alma do Mundo. De acordo com este ponto de partida, a beleza harmoniosa em um corpo material é determinada pela beleza na alma - especialmente pela beleza naquela parte da alma orientada pelo Intelecto Divino. Ficino define a beleza como a perfeição interna do Intelecto Divino, que é equivalente tanto ao bem quanto à harmonia perfeita. Este tipo de beleza perfeita é expressa nas três propriedades harmônicas pitagóricas perfeitas (a saber, 1: 2 (oitava), 2: 3 (quinta), e 3: 4 (quarta)), que aparecem tanto na Alma do Mundo (musica mundana), quanto na alma humana (musica humana) e na música terrena (musica instrumentalis).

No De amore de Ficino, a beleza, equiparada a Deus como o objeto de amor, e o homem que experimenta o amor como um desejo inato por Deus são intimamente ligados. Ele articula este pensamento da seguinte maneira: "esta beleza divina gera, em tudo o que existe, o Amor, ou seja, um desejo por Si próprio (FICINO, 1944 [1469], II, 2, p. 133). Por conseguinte, pode-se afirmar que o desejo no corpo e na mente humana identifica-se com um anseio por uma forma universal, arquetípica, de beleza em Deus. Este desejo universal, inerente nas partes da criação, suscita todo o movimento, tanto no cosmo quanto na alma humana. Ele se manifesta em todas as partes do universo na forma de duas forças opostas, que, juntas, formam um par harmônico: atração e repulsa. Deus deu cada homem um desejo pelo bem, pelo belo e pelo verdadeiro, como uma centelha de uma chama.

Em De amore, Ficino define a beleza como um fenômeno triplo: a beleza se manifesta na alma, no corpo e na música. Estas três formas são revelaçôes de um princípio único, assim como a Trindade é uma manifestação do Divino. Destas três formas de beleza, "aquela referente à alma é percebida apenas pela alma, aquela do corpo, através dos olhos, e a da música, pelo ouvido" (FICINO, 1944 [1469], I, 4, p. 130). 
6. Sobre a teoria ficiniana sobre o poder da música, cf. por ex. FICINO (1496, cap. XXVIIII, p. 69). Para uma interpretação deste capítulo do Timeu de Ficino, cf. WALKER (2003 [1958], p. 8-9).
Com base nesta definiçáo de beleza, Ficino pode conectar o amor tanto com a harmonia das esferas como com a música terrestre. Em sua interpretação da harmonia das esferas, a música interior (musica bumana) corresponde à música cósmica, celestial (musica mundana). Quando o homem estiver completamente equilibrado, os ritmos harmônicos do macrocosmo (os movimentos dos planetas) estaráo refletidos em sua alma humana. Ficino expressa essa percepção da seguinte forma:

Pensamos que a harmonia da música tem sua origem nas revoluçôes ordenadas das esferas planetárias: oito tons são produzidos por oito esferas, e de todas as esferas reunidas surge uma nona harmonia (...). Nossa alma está impregnada, desde o momento de sua criação, pelo princípio dessa música das esferas, porque esta harmonia celeste é inata em tudo o que tem uma origem celestial. Esta harmonia celestial é imitada na terra por diferentes instrumentos e vozes. Este dom nos é dado por amor da Providência divina (FICINO, 1944 [1469], V, 3, p. 181).

No Capítulo VII.12 de De amore, intitulado "Quão prejudicial é o amor terreno", Ficino define o desgosto amoroso e o amor apaixonado como formas de loucura (1944 [1469], VII, 12, p. 230). O amor terreno pode se manifestar na "preocupação ansiosa pela qual os amantes terrenos são dia e noite atormentados." Um excesso de bile negra os leva à "loucura e à paixáo ardente, e, como se fossem cegos, não sabem para onde são lançados, de lá para cá" (Id. Ibid., VII, 12, p. 230). Tal como acontece com muitas outras doenças, o tempo geralmente cura estes tipos de amor doentio, assim como o desgosto amoroso (Id. Ibid., VII, 11 e 12, p. 228-230). Se o tempo não fizer seu trabalho de cura, como no caso de formas de persistentes sofrimento amoroso combinadas com melancolia, há uma série de métodos para purificar a alma destas emoçóes prejudiciais.

Um desses métodos é a busca de distração (Id. Ibid., VI, 12, p. 229). Pelo fato de a música poder manter o homem totalmente em seu poder, a audição de música é um antídoto comprovado contra os pensamentos obsessivos a respeito da pessoa amada ${ }^{6}$. Mas o efeito é geralmente apenas temporário. Uma maneira estrutural de curar o sofrimento amoroso é uma forma de terapia "cognitiva" da música, em que esta é usada 
para se alcançar a uma compreensão mais profunda da realidade e da nossa própria psique.

Para entender a terapia musical de Ficino, é importante, em primeiro lugar, saber que ele inverte a perspectiva moderna sobre a realidade: a percepçáo sensorial consiste em sombras e imagens das coisas reais, que se encontram na realidade harmônica verdadeira - aquilo que está para além da realidade dos sentidos. Para Ficino, a verdade, assim como a percebemos, é, essencialmente, um mundo imaginário, ilusório, que consiste apenas de imagens e aparências. No mundo ilusório em que a alma humana reside temporariamente durante sua vida em um corpo humano na Terra, a imaginação figura como o principal intermediário entre a pseudo-realidade enganosa dos sentidos e a verdadeira realidade do intelecto humano. A imaginação, no entanto, não está exclusivamente ligada ao ilusório, isto é, àquilo que é enganador ou inventado, mas também à fantasia, ou seja, aquilo que é testemunho da criatividade humana. ${ }^{7}$ Em sua capacidade de criar coisas no espírito, o homem se assemelha a Deus Criador, e, nesse sentido, as criaçóes de sua mente parecem mais verdadeiras do que aquilo que é percebido pelos sentidos, ou simplesmente inventado. Na filosofia de Ficino, as coisas inventadas e aquilo em que sua maioria é verdadeiro estão inseparavelmente ligadas. As coisas criativas relacionam-se, na concepção de Ficino, com a criaçáo musical - a saber que aquilo que inventamos na música com base em ideias inatas em nossa alma é mais verdadeiro que aquilo que imitamos dentre as coisas da natureza.

Ficino conecta o Amor, especialmente o amor a Deus e o amor ao próximo, assim como a boa música, com a fantasia isto é, com a verdadeira realidade que subjaz ao mundo perceptível pelos sentidos; com o mundo mais verdadeiro e real. Por outro lado, ele conecta o sofrimento amoroso e a música superficial com a fantasia, com as coisas mais enganosas, relacionadas à ilusão dos sentidos. O sofrimento amoroso é curável por meio da audição de boa música. Para entender exatamente como a terapia musical funciona, no caso do sofrimento amoroso, é preciso examinar mais detalhadamente a teoria de Ficino sobre o som musical. De acordo com ele, sons musicais não são nada mais do que ar em vibração, mas também são decorrências de um princípio de ordenação harmônico que literalmente anima estes sons (1496, p. 69) $)$. Pelo
7. Sobre o imaginário e o fantástico na terapia de Ficino, cf. GIGLIONI (2011, 19-51, p. 20). 
8. Para uma introduçáo à doutrina do ethos musical de Platão e Aristóteles, cf. BARKER (1984, p. 124169 e p. $170-182)$. fato de a música surgir na alma do músico, criada por Deus, ela pode agir diretamente sobre a alma do ouvinte receptor, criada de acordo com o mesmo padrão harmônico. Ficino define esta forma de comunicaçáo musical da seguinte forma:

A música séria preserva e restaura a harmonia das partes da alma, assim como dizem Platáo e Aristóteles ${ }^{8}$ e como nós mesmos habitualmente experimentamos. (...) Considerando que o canto e o som surgem a partir dos pensamentos na mente, do ímpeto da fantasia e da paixáo no coração, e, junto com que eles partiram e temperaram, movem o spiritus aéreo do ouvinte, que consiste na conexão entre o corpo e a alma, eles facilmente movem a fantasia, afetam o coração e penetram os lugares mais recônditos da alma. (FICINO apud WALKER, 2003 [1958], p. 6)

Para reforçar o significado e a origem metafísicos da música, Ficino volta-se novamente para a doutrina Pitagórica da harmonia das esferas. Às consonâncias harmônicas perfeitas (oitava (2: 1), quinta (3: 2) e quarta (3: 4), e ainda a terça maior (4: 5) e a sexta maior (5: 3) é atribuída uma ação benigna e ordenadora sobre a alma humana. As esferas celestes a elas correspondentes estáo de acordo com as regras da harmonia, e perfazem uma música divina, inaudível para nós. Uma música humana que parece ser uma imitação, ou melhor, um eco desta música celeste, impele a alma humana a se elevar até o reino da harmonia divina. É tarefa músico que cura carregar sua música com forças afetivas e mágicas, e com poderes cujo ação seja a mais eficaz sobre a alma de seu paciente:

Os melhores médicos misturam certos fluidos em proporção correta. O resultado é uma variedade de substâncias diferentes, que se fundem em uma nova forma. Além de força elementar. estas mesmas também ganham, de maneira maravilhosa, um valor divino (...). Da mesma maneira os melhores músicos misturam os tons mais graves (como substâncias frias), os mais agudos (substâncias quentes), os médios (substâncias úmidas) e os semiagudos (substâncias secas). Eles as misturam em tal proporção, que, dos diversos tons separados surge uma única forma [musical] composta, que além do valor dos tons acima, ainda recebe um valor divino (FICINO, 1496, p. $70^{v}$ ) 
A maneira como as forças divinas podem ser empregadas na música terrestre para influenciar de maneira positiva o destino humano no De vita (03:21) de Ficino foi exaustivamente estudada por D.P. Walker e por seus sucessores. Pelo fato de suas ideias a respeito da terapia musical para o tratamento do desgosto amoroso serem menos conhecidas, discutirei mais detalhadamente este aspecto de sua filosofia musical.

Baseados em idéias de Ficino sobre o cosmo, procuraremos reconstruir como o desgosto amoroso pode ser curado por meio da música. Ficino parte da ideia de que a mente humana, e em particular a imaginaçáo, pode alterar processos vitais no corpo humano (FICINO, 1944 [1469], VI, 12, p. 229). O pensamento obsessivo a respeito da pessoa amada modifica processos corporais fundamentais do corpo, como a digestão e a circulação. No caso do desgosto amoroso, a concentraçáo implacável e prolongada no ser amado provocada na imaginação do amante consome a quantidade de spiritus em seu sangue, o que leva a um sangue espesso, seco e moroso, repleto de bile negra WALKER, 2003 [1958], p. 4-5). A imagem do ser amado é impregnada na substância maleável do spiritus e, em consequência, se reflete, através do sangue, por todo o corpo, o que leva a um efeito destrutivo.

$\mathrm{O}$ desgosto amoroso evidencia, melhor do que qualquer doença, como a força da imaginação modifica a anatomia e a fisiologia do corpo. No caso desta doença, a atividade superaquecedora da imaginação conduz a uma visão distorcida da realidade, pois o paciente que sofre de desgosto toma como verdadeiras as imagens dolorosas de seu mundo interior perturbado. O desgosto amoroso é, para Ficino, exatamente como todas as outras moléstias: um transtorno psicossomático, pelo qual o sangue é infectado por imagens de spiritus nocivas, que levam a transtornos mentais (PRINS, 2014, p. 165-185).

Devido à grande semelhança entre a música animada pelo spiritus e o próprio spiritus humano, a música pode ajudar a enfrentar doenças como o desgosto amoroso. Pela audição musical, a quantidade ideal de spiritus no sangue pode voltar a ser alcançada. Além disso, durante a audição, as imagens nocivas dos spiritus no sangue humano podem ser substituídas por imagens curativas. Sendo assim, a música tem capacidade tanto quantitativa quanto qualitativa - para temperar o sangue. 
9. Para as ideias de Ficino sobre a sabedoria, cf. RICE (1958, p. 58-92). Para as ideias de Ficino sobre o desgosto e conforto, cf. McCLURE (1991, p. 132154).

10. Cf. RICE (1958, p. 65-67) e McCLURE (1991, p. 149-154).

11. Para um estudo detalhado da recepção de Ficino do Timeu 35b-36b, em especial a divisão do Espírito do Mundo em intervalos harmônicos, cf. PRINS (2014, p. 80-89 e p. 149-164).
$\mathrm{Na}$ cura do desgosto amoroso, um resultado mais permanente só pode ser conseguido ao temperar a força da imaginação. $\mathrm{O}$ paciente deve se apropriar de estratégias para se tornar mais sábio e para se abster de da maior parte dos prazeres sensoriais através da ponderação religiosa. ${ }^{9} \mathrm{O}$ sucesso das terapias de Ficino depende da capacidade do paciente de se abster dos prazeres mundanos, incluindo o amor erótico. De acordo com Ficino, existem dois caminhos que podem levara esta abstenção:

O primeiro [é] através da filosofia moral, em que a alma se afasta das emoçóes que surgem em resposta aos desejos do corpo; o segundo, através da filosofia contemplativa, em que a alma se liberta dos sentidos e da imaginação. Porque a alma encontra-se separada da totalidade[da criação], ela pode, sem a menor dúvida, retornar a si própria, até aos primeiros princípios, e diluir em partes mais simples aquilo que nela mesmo fora unido por pertencimento Porque a alma encontra-se separada da totalidade [da criação], ela pode, sem a menor dúvida, retornar a si própria, até aos primeiros princípios, e diluir qualquer composto que nela tenha sido unido até suas partes mais simples. (FICINO, 1959 [1576], p. 1550).

Em consonância com ideias de muitas religióes e movimentos espirituais, Ficino vê a vida na Terra como um caminho ascendente, em que um homem deve se esforçar para o desapego, para alcançar a felicidade duradoura e para lograr a reunião com o Criador. ${ }^{10}$ Em seu comentário ao Timeu ${ }^{11}$, ele expressa este processo de crescimento espiritual em termos de consonâncias musicais (ver Figura 1).

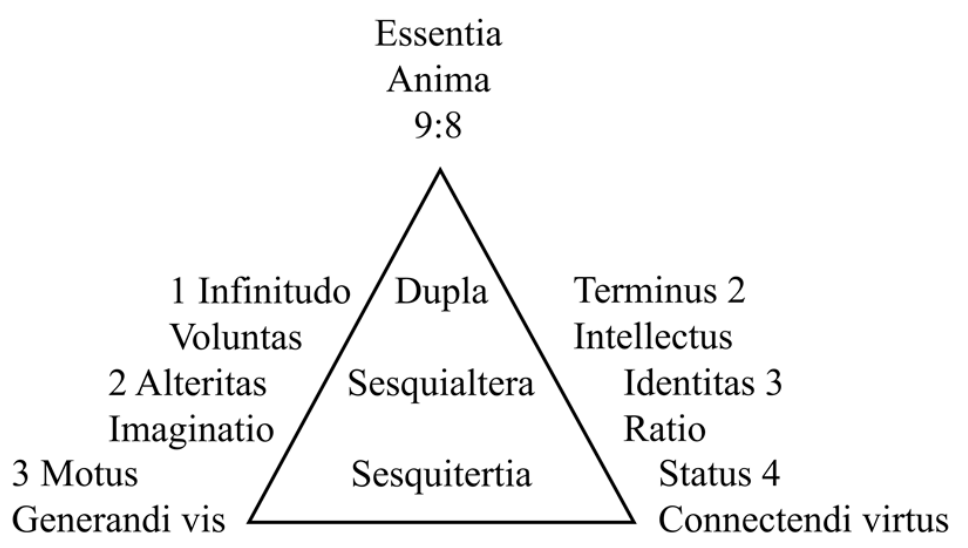

Fig. 1: Reconstrução da concepção de Ficino a respeito da conexão harmônica entre as faculdades cognitivas. Baseado em Marsilio Ficino, comentário ao Timeu, capítulo XXVIII (PRINS, 2014, p. 154) 
O crescimento espiritual ocorre quando o homem ascende os degraus de uma escada a partir do caos e da dissonância da vida cotidiana, que o leva à harmonia perfeita de Deus. Este caminho, que parte das harmonias musicais da quarta (diatessaron) e da quinta (diapente), que, com suas estruturas proporcionais perfeitas expressam a unidade na multiplicidade, leva à forma mais elevada possível de unidade na vida na Terra, simbolizada pela oitava (dupla). De acordo com a citação acima, isto consiste naquilo que "está reunido na alma" sendo, como se segue, "diluído até suas partes mais simples": no nível mais baixo da quarta (4: 3), o homem transcende a matéria; no nível da quinta (3:2), ele encontra um equilíbrio entre a imaginação e a razáo; no nível da oitava (2: 1), ele encontra um equilíbrio entre a vontade e o intelecto. Neste processo, a imaginação não apenas é reprimida pela razão, mas esta imaginação "razoável" é, por sua vez, subordinada a uma mistura equilibrada entre a vontade e o intelecto. Durante este processo, libertamo-nos paulatinamente do imaginário, isto é, de imagens que vêm do mundo exterior, ou do mundo interior distorcido, tal como no caso do sofrimento amoroso. Durante este processo, a beleza do ser amado, assim como da música sonora, vai se tornando cada vez mais irrelevante e abre caminho para a beleza eterna do amor absoluto e do silêncio da música inaudível das esferas.

A audição da música repleta de consonâncias é capaz, de acordo com Ficino, de apoiar e apressar o processo de elevação espiritual. Este é, em última análise, o motivo principal pelo qual a música é um antídoto comprovado contra o desgosto amoroso. Ouvir música pode, realmente, ter efeito curativo, mas para aqueles que almejam alcançar a harmonia física e psíquica, a música náo constitui mais do que uma ferramenta de auxílio. A paz de ânimo genuína só pode ser alcançada mediante a fé sincera em Deus e em uma vida piedosa. Finalmente, a vida deve girar em torno da fé, da esperança e do amor verdadeiro e náo ofuscado.

\section{MÚSICA COMO REMÉDIO PARA O DESGOSTO AMOROSO EM ARTEMISIA DE CAVALLI}

No século XVII, a terapia musical para o desgosto amoroso é, em grande parte, um clichê musical, verbal e visual da 
12. A história da recepçáo do De amore de Ficino foi amplamente estudada. Sobre a influência de suas ideias sobre o desgosto amoroso na literatura do início da era moderna, cf. WELLS (2007, p. 1-60) e DAWSON (2008, p. 130-136).

13. $\mathrm{Na}$ Biblioteca Nazionale Marciana em Veneza encontram-se ediçóes antigas do De amore de Ficino (por exemplo, uma cópia da traduçáo italiana: Marsilio Ficino, Sopra lo amore o ver'Conuito di Platone, Firenze: Néri Dortelata, 1544), a partitura original de Artemisia (Cavalli, Artemisia, 1641-1660, Rism A/II (9.a ed.)) e o libretto original da ópera (Nicolò Minato, Artemisia, 1656). Mais pesquisas deverăo ser capazes de comprovar se Minato e/ou Cavalli travaram contato direto ou indireto com a filosofia de Ficino.

14. Para informaçōes gerais sobre Artemisia de Cavalli, cf. WALKER e ALM (2014); cf. ainda SCHULZE (2010, p. 8-9).

15. Sobre o lugar de Cavalli na história da ópera seiscentista italiana, cf. ROSAND (2013). cultura europeia, que remonta à longa tradiçáo musical relativa a teorias sobre o amor e sobre a harmonia universal. ${ }^{12}$ No entanto, também quase não subsistem, registros, prescrições ou outros tipos de recomendaçóes deste período, que possam de servir de base para investigar qual tipo de música de fato era utilizada para tratamento dos casos obsessivos de paixão ou desgosto amoroso (AUSTERN, 2000, p. 215).

Felizmente, na partitura da ópera Artemisia ópera (1657), de Francesco Cavalli, o dueto "Cor mio che sarà" oferece uma boa ideia de como as teorias de filósofos como Ficino, no século XVII foram transformadas em clichés musicais. Embora eu não tenha encontrado evidências diretas de que Cavalli tenha sido diretamente influenciado por Ficino, é muito provável que ele tenha travado conhecimento, de uma maneira ou de outra, com o muito popular De amore. ${ }^{13}$

As óperas de Cavali eram inovadoras em seu tempo, por tratarem de intrigas eróticas. ${ }^{14}$ Mas como Ficino se preocupava especificamente em restaurar a ordem moral na alma humana, a ação nesta ópera visa diretamente restaurar a ordem moral, em nível social. A trama de Artemisia é uma alegoria moral, que responde à tendência italiana desta época, de conferir à ópera um caráter didático, elevando-a acima do mero divertimento superficial. ${ }^{15}$ Cavalli compôs Artemisia em conjunto com o libretista Nicolò Minato em primeira instância para o público veneziano, que, desde as primeiras apresentaçóes operísticas públicas, mostrava-se muito interessado em temas políticos. Um dos assuntos que mais agradava estes ouvintes era o da instituição de Veneza como república, por eles considerada a melhor forma de administraçáo de estado. A partir desta preferência, reis e rainhas nas óperas de Cavali eram frequentemente rebaixados à categoria de déspotas, náo possuidores da virtude do autoconhecimento nem do autocontrole, necessários para o bem estar e para o sucesso pessoal e político. Nesta concepção ressoa um eco da República platônica (389 d-e), em que são louvadas as virtudes como a moderação, a complacência e o controle sobre desejos como fome, sede e impulso sexual. O equilíbrio das emoçóes e das necessidades é um conceito-chave que fundamenta tanto o estado ideal quanto a disposiçáo ideal da alma humana. De acordo com a República (432 a), moderação e prudência são os princípios que permitem alcançar a harmonia, isto é, o equilíbrio 
adequado de forças diversas, seja para a convivência social, seja para a alma humana.

O tema central em Artemisia é a tensa relação entre os ideais políticos e psicológicos e a realidade dominada pelo poder, pelo amor erótico pela honra SCHULZE, 2010, p. 8-12). Na ópera, a protagonista Artemisia é submetida a uma grande mudança de caráter, caracterizada com base nestes dois pólos. No início da ópera, ela aparece como uma rainha, educada por seu professor Indamoro sob a ilusão de que seja superior aos outros. Nesta fase, seu amor para com o rei Mausolo, embora sincero, não é determinante em suas açóes. Após a morte deste, Artemisia toma medidas drásticas para confirmar a imagem que tem de si própria. Ela constroi um mausoléu (uma das sete maravilhas do mundo) para seu falecido marido, e jura vingança contra Meraspe, que ela suspeita tê-lo assassinado. O amor que Artemisia sente por Clitarco (que, ajustando-se àtradição operística do disfarce, não é outro senão seu inimigo mortal Meraspe), ajuda-a a lidar com sua dor. Mas o amor erótico que ela sente por Clitarco ao mesmo tempo prejudica a sua capacidade de liderança: a partir do momento em que deixa de dominar seus próprios sentimentos, ela não consegue desempenhar adequadamente o seu papel de rainha. Além disso, Artemisia tem dificuldades para com o fato de que seu amante é socialmente inferior a dela. Inicialmente, ela procura escapar dos efeitos adversos deste amor, proibindo todos os relacionamentos amorosos em sua corte. Ela deseja endurecer seu coração e se empenha totalmente na condução da guerra, mas esta forma de repressão surte um efeito reverso.

A moral da história é clara: em uma monarquia, o estado está submetido à disposição emocional de seu regente. Esta situação indesejável, que se ajusta completamente ao gênero operístico, é então resolvida através da terapia musical. No dueto Cor mio che sarà ("Meu coração, o que acontecerá?"), entre Artemisia , a rainha viúva , e Eurillo , um de seus músicos, é possível observar uma forma de terapia musical, em que estão refletidas algumas das ideias neoplatônicas acima discutidas a respeito do temperamento da alma. ${ }^{16}$

Torturada por desgosto amoroso, Artemisia, no início do dueto, ordena a seu bardo Eurillo, que cante, para que ela se acalme. Ela almeja que "um pouco de canto talvez abrande a amargura de seu desconsolo". Artemisia já náo suporta a inse-

16. Sobre a história do surgimento desta canção, cf. ROSAND (2013, p. 90). 
gurança mortal que acompanha o sofrimento amoroso ('Meu coração, o que acontecerá?') e ordena a Eurillo: "canta uma pequena cançáo, vamos.". O conteúdo, tanto verbal quanto musical, da melodia que Eurillo apresenta a seguir, é terapêutico. Eurillo explica a Artemisia que, se ela desejar ser curada dos tormentos do amor, deve tranquilizar seu coraçáo e ansiar por compaixáo. A catarse de emoçóes negativas conduzirá ao alívio ao consolo, e a esperança agirá como antídodo contra as setas envenenadas do Amor cego, disparadas contra seu coração e contra sua razão. Quando a imaginação de Artemísia for controlada pelo discurso, assim como na filosofia de Ficino (ver fig. 1), os sentimentos dolorosos e seus efeitos incapacitadores desaparecerão, e Aretmisia voltará novamente a saber exatamente o que deve ser feito.

Cavalli, Artemisia

Ato 3, cena IX

Artemisia, Eurillo (CAVALLI, 2010, p. 108-109;

trad. Mônica Lucas)

\section{Artemisia}

Cor mio che sarà?

La mente agitata,

E l' alma turbata.

Consiglio on hà.

Cor mio che sarà?

Cantisi un poco, ò là.

\section{Eurillo}

Siam qui Regina.

\section{Artemisia}

Potrian voci canore

La forza raddolcir del mio dolore.

\section{Eurillo}

Chiedete, e sperate

Amanti mercè,

Sì crudo non è

Il cieco volante,

Qual voi lo stimate.

Chiedete, e sperate.

A torto incolpate

D'ingrato il Destin. 
Il nume bambin

Udirvi non puote,

Se voi non parlate.

Chiedete, e sperate.

\section{Artemisia}

Par ch'il cor mi favelli. Eurillo prendi

Vanne a Clitarco, e dì che tutto Adempia

Ciò, che qui leggerà.

\section{Eurillo}

Pronto ubdisco.

\section{Artemisia}

(Ma io cosi m’avvilisco!

Io così mi deprimo!) Eurillo!, Eurillo!

Vieni, porgimi il foglio.

Parti, ch'altro non voglio.

\section{Eurillo}

La fatica risparmio.

Artemisia (legge)

Clitarco, io porto in seno un core astretto

Dal fato a incenerir nétuoi ardori.

Son ingrate ad Alindo: odio, rietto

Il prencipe di Lida, il re de'Mori

Solo per te. Pensa chi son, chi sei,

E insuperbisci de gl'amori miei.

Tolga il Ciel che tai note

Legga Clitarco.

\section{Artemisia}

Coração meu, o que será?

A mente agitada

E a alma turvada

Não podem decidir.

Coração meu, o que será?

Cante-se um pouco, entáo.

\section{Eurillo}

Estou aqui, rainha. 


\section{Artemisia}

Vozes canoras

Pudessem, talvez, adoçar minha dor.

\section{Eurillo}

Acreditai e esperai

O favor do amante,

Tão cruel não é

O cego voador,

Quanto pensais ser.

Acreditai e esperai.

Erroneamente culpais

De ingrato o Destino,

O Deus menino

Não poderá vos ouvir,

Se vos não falardes.

Acreditai e esperai.

\section{Artemisia}

Meu coração me falou. Eurillo, ouve: Vai até Clitarco, e diz que execute tudo Aquilo que aqui lerá.

\section{Eurillo}

Prontamente obedeço.

\section{Artemisia}

(Mas desta maneira me humilho!

Assim me rebaixo!) Eurillo!, Eurillo!

Vem, devolve-me a carta.

Parte, não desejo outra coisa.

\section{Eurillo}

Poupo a fadiga!

$\operatorname{Artemisia}(l \hat{l})$

Clitarco, em meu seio há um coração apertado

Pronto a incendiar-se em teu fogo.

Tornei-me ingrata a Alindo; odiei, desprezei

O principe de Lida, rei dos Mouros

Somente por ti. Pensa em quem sou, em quem és

E orgulha-te de meu amor.

Que o ceu proíba que

Clitarco leia estas notas. 
Este dueto é um belo exemplo de como Cavalli utiliza o material musical para expressar uma mudança no caráter da Artemisia (fig. 2). Geralmente ele utiliza a forma ária para expressar o mundo interior de um personagem e o recitativo para contar a história; contudo, nesta cena, a situação está invertida. A cena começa com um recitativo em que Artemisia suspira, sem mais saber como lidar com seu desgosto amoroso.

Os sintomas do desgosto, como turbulência e incerteza, são representados na melodia através de figuras interrogativas (cor mio che sarà: figura melódica ascendente e suplicante ré-mi, seguida por uma figura interrogativa lá, ré, si) e através de notas longas sustentadas do acorde de dominante (fá \# repetido em agitata e turbata), que aumentam a tensão harmônica e pedem resolução. A melodia está em nítido contraste com a figura ostinato repetitiva em sol na linha do baixo, que representa a verdade, e que destoa táo fortemente do mundo interior de Artemisa, cegado pelo amor. ${ }^{17}$

Quando Artemisia pede a seu bardo que cante uma música para que acalmasse seu coraçáo atormentado pelo amor, ela expressa sua dor (Mio dolore) na melodia com uma modulaçáo para sol menor, gerando, na melodia, o intervalo sib - fá\#, ou seja, uma quarta diminuída, muito adequadamente denominada diabolus in musica.

A ária cantada, em seguida, por Eurillo, para trazer sua rainha de volta à razão, tem a forma $\mathrm{ABA}$ e está em compasso simples $3 / 4$. Eurillo é acompanhado por dois violinos, que, na parte A tocam suas melodias em terças paralelas, harmônicas. A parte B contrasta com as partes A. Nesta, Eurillo constrói com sua voz a palavra volante - um longo melisma que representa, com seus movimentos volantes e desorganizados, o deus alado Amor. Como a música se assemelha tanto à emoção do amor, ela pode, através da imitação, incitar ou acalmar a emoção e a paixão erótica livre e imoderada. Os movimentos desordenados do deus Amor, que representam o mundo interior de Artemisia, são, portanto, acalmados e dominados pela ordem clara, na repetição da parte A.

A canção de Eurillo ilustra como o compositor, através do uso de uma doutrina musical dos afetos, em que tonalidades específicas e figuras musicais são acopladas a efeitos específicos, configura um processo de catarse. ${ }^{18}$ Desde o tempo
17. Nas óperas de Cavalli, frequentemente a linha do baixo comenta a parte cantada nas vozes superiores, permitindo que o ouvinte reconheça exatamente o que ocorre: se o personagem é tomado por louco, se mente, se esconde algum segredo (SCHULZE, 2010, p. 9).

18. Para a teoria dos afetos nas óperas de Cavalli, cf. VECCHIA (2011). 
19. Cf. PLATÃO. República, $\quad 399 \mathrm{a}-\mathrm{b} \quad \mathrm{e}$
FICINO (1989 [1489], p. 354-363). de Platáo e Aristóteles, modos musicais são associados com afetos, e a música é utilizada tanto para evocar um afeto ou disposição quanto para acalmá-lo ou contrariá-lo. A música de Eurillo relaciona-se à música dórica da República de Platão e à música dórica terapêutica de Ficino, que, por sua vez, se relaciona à energia positiva e harmonizante do sol. ${ }^{19}$

No recitativo seguinte ("Meu coraçáo me falou"), parece que a força ordenadora da música trouxe Artemisia, cegada pelo amor, de volta à razáo. As cordas do coração de Artemisia não vibram mais no modo agitado do tormento amoroso, mas em pulso regular, adequado ao estado (dórico) da tranquilidade de ânimo. Contudo, os papeis sociais neste recitativo estáo invertidos: a rainha Artemisia é dominada pela música de seu servo Eurillo. Com voz calma e suave (na partitura, expressa por muitas palavras na mesma altura sonora), ela ordena a Eurillo que vá a seu amado Clitarco, obedecendo às suas ordens. Antes da confissáo de Artemisia, na carta a Clitarco, Cavalli modula para a tonalidade de sol menor. $\mathrm{Na}$ carta a Clitarco, ela admite ter causado injustiça a pessoas a seu entorno, por cegueira de 2001amor e ódio. A açáo ordenadora da música é apenas temporária; a ópera está longe de terminar e a carta leva a diversas novas complicaçôes. 
Scena IX
ARTEMILA, EURLLLO

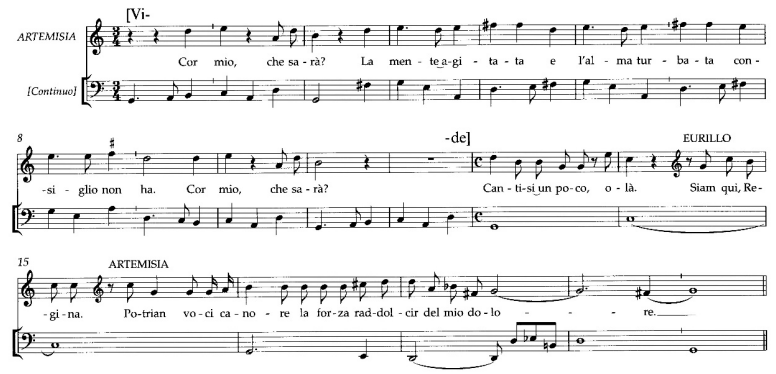

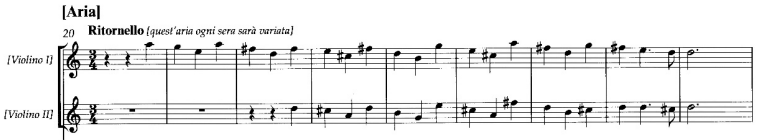

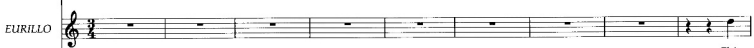

IContinuo $\left[\sum_{1}:\right.$ :

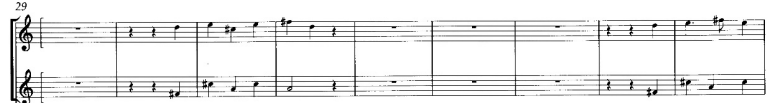

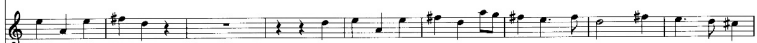

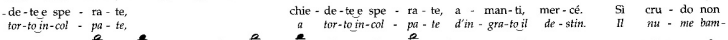

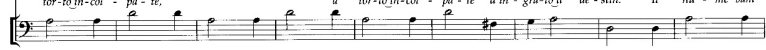

136

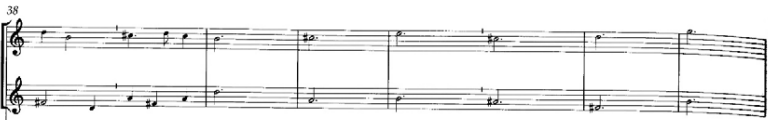

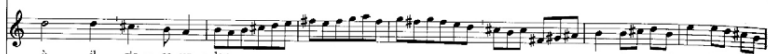

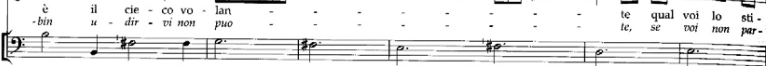

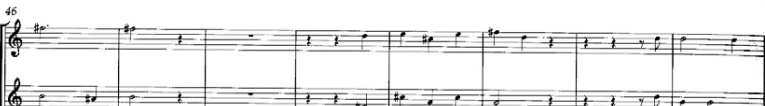

色然

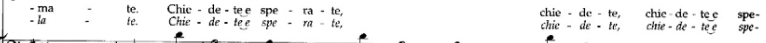
[E:

(1)

ARTEMISIA tContinuo [ 

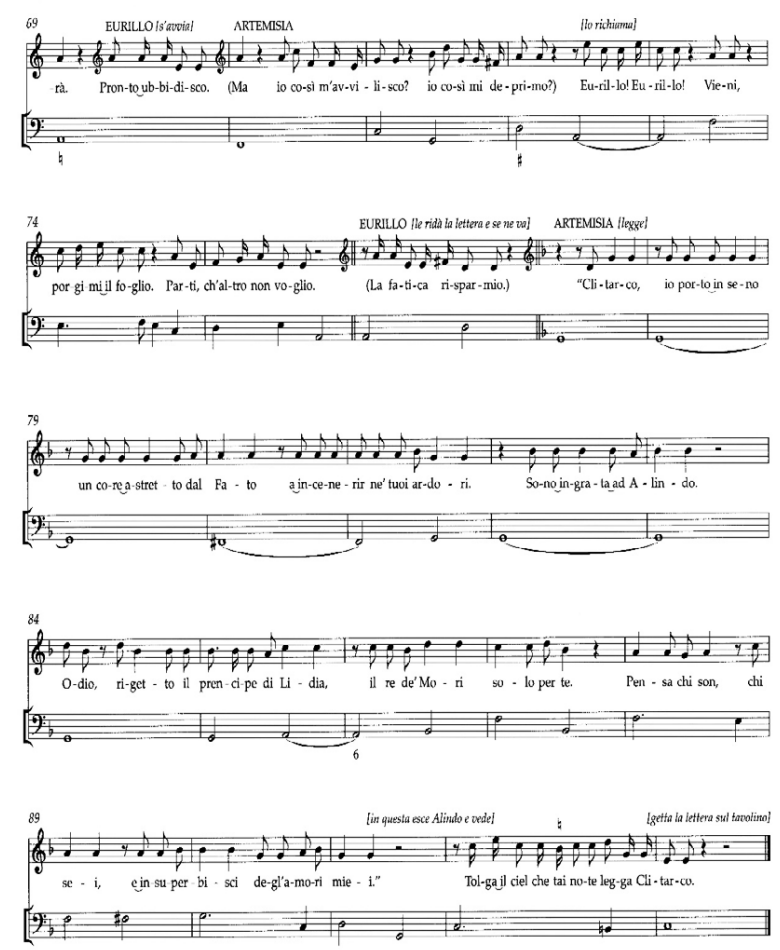

20. Cf. SCHULZE (2010, p.11-12).

Fig. 2: Cavalli, Artemisia, Ato 3, Cena ix: dueto: Artemisia e Eurillo (CAVALLI, 2013, p. 35-37)

A ópera tem um final aparentemente feliz: todos se reúnem com suas metades. Mas também fica claro que as forças do poder e do amor erótico de modo algum se excluem mutuamente. Afinal, a harmonia cósmica e o amor universal superam a força do amor erótico humano, assim como ocorre na filosofia religiosa de Ficino. Apesar de esta concepçáo de amor de distanciar de nossa visão romântica sobre o amor erótico, esta foi certamente a mensagem moral que prevaleceu junto ao público veneziano naquela época. ${ }^{20} \mathrm{~A}$ breve apresentação, neste artigo, da história das ideias da terapia musical associadas ao tratamento do desgosto amoroso, deixa claro porque o público veneziano saía satisfeito da apresentação.

\section{CONCLUSÃO}

No pano de fundo destes dois exemplos bastante diversos com relação ao tratamento do desgosto amoroso, figuram as 
mesmas teorias sobre harmonia e temperamento de emoçóes, - teorias que mantiveram influência no pensamento ocidental sobre a música durante vários séculos. A música, nos dois exemplos, é um meio eficaz de para recuperar o equilíbrio original entre a alma e o corpo, perdido por causa da paixáo erótica excessiva.

Ficino parte do pressuposto de que a sabedoria necessária para não cair vítima do desgosto amoroso ou para ser curado dele é, ao mesmo tempo, uma virtude de caráter intelectual e prático. Em sua filosofia, ele não discorre apenas sobre aquilo que se deve saber para se tornar sábio e moderado, mas também sobre o que se pode fazer para adquirir esta sabedoria. Neste contexto, a música, em especial a audição e a prática de música astrológica e religiosa, tornou-se um meio para alcançar o conhecimento mais elevado. Contudo, permaneceu em sua filosofia uma crença arraigada em Deus, tido, afinal, como o meio mais garantido contra o desgosto amoroso. Em Cavalli, foi possível observar a mesma relação entre música e o desgosto, embora totalmente fora do contexto religioso. Em Artemisia, o desgosto amoroso consiste em uma afecçáo puramente humana que pôde ser curada pela audiçáo de música secular. Se, para Ficino, a cura do desgosto amoroso leva a um nível mais elevado de iluminação espiritual, em Cavali, ela conduz à transição adequada para a ordem diária. Contudo, ambos os exemplos, a meu ver, pertencem a um e o mesmo universo de conceitos que versam sobre a influência moral da música na alma humana.

Tanto a filosofia do amor de Ficino quanto a ópera Artemisia, de Cavalli, testemunham uma crença profundamente enraizada de que a música tenha poder de influenciar intimamente a alma humana nos aspectos moral e médico. Ambos estavam convencidos de que tanto o amor quanto a música eram fenômenos ambivalentes, que poderiam elevar ou degradar o ser humano. A música poderia tanto incitar quanto mitigar o amor. No caso do desgosto amoroso, a música poderia, ainda, suscitar a esperança de o amor ser correspondido, desviando a mente da ocupação obsessiva com o amante, ou até mesmo levar à libertação da força ofuscante da paixão. No último caso, prescrevia-se o uso de formas específicas de música que lidavam com emoçóes nocivas, ligadas aos pensamentos e emoçóes relativos à pessoa amada. Tanto a terapia musical de Ficino quanto a música de Cavalli visavam esta forma de catarse. 


\section{REFERÊNCIAS BIBLIOGRÁFICAS}

AUSTERN, Linda Phyllis. Musical Treatments for Lovesickness. In: HORDEN,

Peregrine (ed.). Music as Medicine: The History of Music Therapy Since Antiquity. Aldershot: Ashgate, 2000, p. 195-245.

BARKER, Andrew. Greek Musical Writings. Cambridge: Cambridge University Press.

1984 (v. 1).

CAVALLI. Artemisia: Dramma per Musica. Kassel: Bärenteiter, 2013 (ed. Hendrik Schulze).

DAWSON, Lesel. Lovesickness and Gender in Early Modern English Literature.

Oxford: New York: Oxford University Press, 2008.

FICINO, Marsilio. Commentaria in Platonem. Firenze: Laurentius (Francisci) de Alopa, 1496.

Commentary on Plato's Symposium [De amore ou Commentarium in Convivium Platonis] Columbia [Firenze]: The University of Missouri Studies, 1944 [1469]. Trad. Sears Reynolds Jayne.

Medicina corpus, musica spiritus, theologia animum. In: The Letters of Marsilio Ficino. London: Shepheard Walwyn, 1975, vol.1. Trad. membros do Language Department of the School of Economic Science, London.

1959 [1576]

Opera Omnia. Turin [Basel]: Heinrich Petri,

Three Books on Life [De Vita triplici]. Binghamton, NY: Medieval and Renaissance Texts and Studies/Renaissance Society of America [Firenze: Antonio di Bartolomeo Miscomini], 1989 [1489]. Trad. Carol V. Kaske e John R. Clark.

GIGLIONI, Guido. Coping with Inner and Outer Demons: Marsilio Ficino's Theory of

the Imagination. In: HASKELL, Yasmin (ed.). Diseases of the Imagination and Imaginary Disease in the Early Modern Period. Turnhout: Brepols, 2011, p, 19-51.

KLIBANSKY, Raymond, E. Panofsky e F. Saxl. Saturn and Melancholy: Studies in the

History of Natural Philosophy, Religion, and Art. New York: Basic Books, 1964. 
McCLURE, George W. Sorrow and Consolation in Italian Humanism. Princeton, NJ:

Princeton University Press, 1991.

MINATO, Nicolò. Artemisia: Dramma per Musica (libreto). Kassel: Bärenteiter, 2013 (ed. Sara Elisa Stangalino).

PLATÃO. A República. Lisboa: Gulbenkian, 2001.

PRINS, Jacomien. Echoes of an Invisible World: Marsilio Ficino and Francesco Patrizi

on Cosmic Order and Music Theory. Leiden: Brill, 2014.

RICE Jr., Eugene F. The Renaissance Idea of Wisdom. Cambridge, Mass.: Harvard

University Press, 1958.

ROSAND, Ellen. Opera in Seventeenth-Century Venice: the Creation of a Genre.

Berkeley and Los Angeles, 1991. (ed.). Readying Cavalli's Operas for the Stage:

Manuscript, Edition,

Production. Farnham: Ashgate Interdisciplinary Studies in Opera, 2013.

SCHULZE, HENDRIK. Artemisia. In: CAVINA, Claudio. CAVALLI. Artemisia. CD

GCD 920918. Mondovì, 2010, p.8-12.

VECCHIA, Francesco dalla. Key Symbolism in Francesco Cavalli's Aria's. 213 p. Tese (Doutorado em Música). Iowa University. Iowa, 2011.

WALKER, Daniel. Spiritual and Demonic Magic from Ficino to Campanella. University Park [London]: Pennsylvania State University Press [Warburg Institute], 2003 [1958], p. 3-24.

WALKER, Thomas e Irene Alm. Francesco Cavalli. In: Grove Music Online. Disponível em: <http:// http://www.oxfordmusiconline.com. Acesso: 31 de dezembro de 2014.

WELLS, Marion. The Secret Wound: Love-Melancholy and Early Modern Romance.

Stanford, Calif: Stanford University Press, 2007. 